\title{
EXPLORING MUNICIPAL UTILIZATION OF SOCIAL MEDIA IN PERFORMANCE MEASUREMENT AND MANAGEMENT
}

\author{
Tamara Dimitrijevska-Markoski \\ Ph.D., Assistant Professor, Department of Political Science \\ and Public Administration, Mississippi State University. \\ Address: 192 Bowen Hall, P.O. Box PC, \\ Mississippi State, MS 39762, USA. \\ E-mail: tamara.markoski@msstate.edu
}

\section{Abstract}

In the last decade, governments have expanded the utilization of performance measurement and reporting techniques to include the application of social media activities. While each of the two trends has been explored distinctly, their intersection is often neglected. Through the analysis of the official Facebook pages from a random sample of Florida Benchmarking Consortium (FBC) participating municipalities, this study explores the utility of social media in the collection and dissemination of performance information. The results of the analysis suggest an insufficient application of social media for performance-related issues. Out of the three main social media strategies typically available to governments, 'push, pull and networking strategies,' FBC local governments typically employ the 'push strategy,' wherein the municipality reports performance directly to citizens, and to a lesser extent, the 'pull strategy,' wherein the municipality attempts to engage potentially interested citizens' attention. The 'networking strategy' was not utilized, indicating the potential need for a greater use of social media platforms to engage citizen involvement in the performance measurement and management process.

Keywords: Facebook; Florida Benchmark Consortium (FBC); local government; performance measurement and management (PMM); performance measurement reporting; push, pull and networking strategies; social media.

Citation: Dimitrijevska-Markoski, T. (2018). Exploring Municipal Utilization of Social Media in Performance Measurement and Management. Public Administration Issues, Special Issue II (electronic edition), pp. 98-106 (in English); DOI: 10.17323/1999-5431-2018-0-6-98-106 


\section{Introduction}

The use of the internet and the proliferation of social media in all spheres of life is now the norm rather than the exception. Social media platforms Facebook, Instagram, and Twitter are routinely exploited by ordinary individuals as well as businesses, nonprofit organizations and governments. In order to best engage the now technically savvy public, local governments are beginning to embrace the utility of social media. Facebook is the most popular social platform (Ellison, \& Hardey, 2014) and second most visited site in the world (de Zuniga, Jung, \& Valenzuela, 2012). Moreover, Facebook is positioning itself as a key feature of e-government (Linders, 2012) with $87 \%$ of municipalities in the US using this platform from as far back as 2011 (Mossberger, Yonghong, \& Crawford, 2013). The use of social platforms facilitates the process of marketing a municipality and its activities while offering new opportunities for engagement between the government and citizens (Hand, \& Ching, 2011; Linders, 2012).

An important but often neglected use of social media is the capacity for performance measurement and reporting. Today, governments are increasingly pressured to measure performance within a wide range of strategies to stimulate the use of the performance information (Dimitrijevska-Markoski, forthcoming). While factors associated with effective performance measurement and management (PMM) have been explored, the existing research is lacking in the examination of the extent to which social media has been used in performance measurement and reporting.

In general, citizens have very low involvement in the PMM process. At the dawn of social media, Ho (2006) found that only 17 percent of Mayors involved citizens in the measurement of performance, which is not surprising as the mechanisms for worthwhile interactions was time-consuming and inefficient. As society and the utility of social media has evolved, De Lancer Julnes (2013) suggests the necessity and inevitability of "find[ing] new approaches to engage citizens and implementing performance-based management" (p. 83). While there are a wide range of efforts to integrate performance management and citizen participation, the inclusion of citizens input into the PMM process is relatively new (Heikkila \& Isett, 2007). To better understand this dynamic, this study explores the above intersection using the social media platform Facebook in government performance measurement and reporting. As Facebook is the preeminent social media application offering the opportunity for collective creation and many-to-many communication (Ellison \& Hardey, 2014), this study explores the extent of its use for performance related issues within a municipal context.

The data for the analysis is obtained through a random sample of municipalities within the Florida Benchmarking Consortium (FBC). As FBC member municipalities voluntarily join the consortium, there is an inherent assumption that each are strongly concerned with performance management and therein collectively represent an exemplar group for this examination. Moreover, this study uses Mergel's (2013, p. 127) social media tactics as a framework for "a) representation of the agency, b) engagement of citizens, and c) networking with the public," (respectively push, pull and networking strategy), to examine the dominant strategies used by FBC municipalities. 


\section{Citizens' Involvement in Performance}

\section{Measurement and Management}

The involvement of citizens in performance measurement and reporting offers benefits for democratic governance while explicitly strengthening its relevance (Pierce, 2011). When citizens are involved in the process of performance measurement and management, it allows for the incorporation of their views on issues important to them (Woolum, 2011). Overall, the inclusion of citizen perspectives in the PMM process adds value to good governance in the process, allows for government responsiveness to the citizens' needs, and leads to a more effective collaboration focused on the issues that are important to the community heightened by better-informed decisions (De Lancer Julnes, 2013; Fung, 2015; Gunawong, 2015; Holzer \& Kloby, 2005; Woolum, 2011). Citizen-driven performance measurement involves the public in the development of the measures and reporting processes, as well as providing palpable feedback on the performance reports. This allows citizens to get involved in administrative and policy implementation stages other than just influencing the policy making process (Heikkila \& Isett, 2007; Pierce, 2011). Therefore, it helps managers to manage for results once they get performance information, but also increase external support through the sharing of performance information (Heikkila \& Isett, 2007). In addition, citizen involvement also contributes to amplified feelings of belonging within a community, which increases satisfaction, trust and accountability performance (de Zuniga, Jung \& Valenzuela, 2012; Heikkila \& Isett, 2007; Pierce, 2011). Although an increasing number of governments involve citizens in performance discussion, there is often little understanding on the realized or potential engagement of citizens in those processes (Woolum, 2011).

There are several approaches to citizen involvement embraced through PMM such as open public meetings and hearings, advisory committees or special task forces, focus groups, citizen surveys and more recently the use of e-government initiatives (Fung, 2015; Holzer \& Kloby, 2005; Heikkila \& Isett, 2007; Woolum, 2011). Use of citizen surveys is important for performance measurement with approximately 43 percent of cities and counties routinely measuring citizen satisfaction (Dalehite, 2008, p. 892). Unfortunately, there is no such estimate in the utilization of social media platforms. The use of Facebook offers several distinct advantages over surveys and town meetings. While surveys are generally a static one-way communication (Woolum, 2011), Facebook allows for almost real-time interaction, two-way communication and a platform for the exchange of information and dialogue. Like surveys, Facebook users at municipal sites are self-selected, however, the platform allows for a greater contextual portrait of the magnitude of satisfaction with the opportunity to initiate a conversation. Another advantage of Facebook over forums or open-invitation town meetings which often attract a small group of uniquely motivated participants (Woolum, 2011), is the ease of communication and availability to a wider group of citizens in a less restrictive timeframe. Simply, the use of Facebook is a relatively low cost alternative for providing feedback or input without the inconvenience of physically attending a meeting within a limited, strict time context (Heikkila \& Isett, 2007; Pierce, 2011). 


\section{Use of Facebook by Local Governments}

To connect with citizens, governments have used e-government technologies such as websites, listservs and RSS feeds (Hand \& Ching, 2011). However, most utilized technologies are one-way communications where governments present information and citizens have access (Hand, \& Ching, 2011). However, if properly utilized, social media enables citizens to be recipients, critics and producers of information (Hand \& Ching, 2011; Hofmann, Beverungen, Räckers \& Becker, 2013). In addition to enabling bottom-up communication, social media offers a vastly efficient many-to-many model of communication (Hand \& Ching, 2011). This means that communication can travel from government to many citizens, from many citizens to government and between many citizens (Hand \& Ching, 2011).

Facebook is the largest social media platform in the world and has more than 900 million pages, more than 500 million active users (Hand \& Ching, 2011) and more than 100 million unique visitors per month (Mergel, 2013). According to Pew Research Center, 63 percent of Facebook users visit their account at least once a day with 40 percent doing so multiple times each day (Bonsón, Royo \& Ratkai, 2015). The adoption of Facebook by US cities grew exponentially from 13 percent in 2009 to 87 percent in 2011 (Mossberger, Yonghong \& Crawford, 2013). Although Facebook offers advantages for direct interaction with citizens, many governments do not fully utilize the platform (Hofmann, Beverungen, Räckers \& Becker, 2013).

As social media began to gain traction in 2009, President Obama gave the directive demanding federal government agencies "harness new technologies' in order to become more transparent, collaborative and participatory" (Mergel, 2013, p. 123) and this study makes the assumption that Facebook is one of the better contemporary technology platforms in achieving this goal. While there are studies that examine the influence of social media, such as Facebook and Twitter, on citizen engagement (Bonsón, Royo \& Ratkai, 2015; Hand \& Ching, 2011), the utilization of social media as a conduit for citizens to participate in performance measurement and reporting management has been limited (Woolum, 2011). Mossberger, Yonghong \& Crawford (2013) analyzed the 75 largest US Cities under the context of the Mergel (2013) "push, pull and networking strategies" and found that push strategies still predominate government use. Similarly, Hofmann, Beverungen, Räckers \& Becker (2013) analyzed the Facebook sites of the of 25 largest German cities and found that out of 15,941 total posts "only 14 posts encouraged citizens to co-design a government service" (Hofmann, Beverungen, Räckers \& Becker, 2013, p. 392). Therefore, this study hopes to clarify the way US cities that are generally concerned with performance use Facebook to collect or report performance information.

\section{Conceptual Framework}

Previous citizen involvement research in performance issues has relied on the New Public Service normative theory of governing (Woolum, 2011). The New Public Service theorists recognize the importance of citizens and the responsibility of government to address their interests while building a relationship of trust 
with them (Woolum, 2011). This study acknowledges the benefits of citizen involvement in the process and classifies the performance-related posts using the typology developed by Bonsón, Royo, \& Ratkai, (2015) categorizing three dominant types of communication: citizen to government $(\mathrm{C} 2 \mathrm{G})$; government to citizen (G2C); and citizen to citizen (C2C). This is in line with the typologies of Linders (2012) and Mergel (2013). Namely, Linders (2012) typology of citizen e-participation includes: citizen sourcing, government as a platform, and do-it-yourself government, while Mergel (2013) used three predominant tactics: 1) representation, 2 ) engagement) and 3) networking. Although each uses slightly different terms, the concept and criteria of each typology group remains relatively the same. In particular, the first criterion is the PUSH strategy (Government to citizen or representation tactic) where the government uses media channels to notify users about issues (Mergel, 2013). The second criterion is the PULL strategy (citizen to government or engagement tactics) and aims for interaction with users organically, encouraging users to participate in the content creation (Mergel, 2013). The third strategy is CITIZEN TO CITIZEN (networking strategy) which leaves the discussion to users and includes both push and pull strategies (Mergel, 2013). Integrating the above, this study will analyze performance-related posts at municipal Facebook pages by classifying each as either a Push (Government to Citizen), Pull (Citizen to Government) or Networking (Citizen to Citizen) interaction.

\section{Data and Methodology}

This cross-sectional, exploratory study analyzes the official Facebook pages of a random sample of FBC local governments. The FBC was established in 2004 as a voluntary network of local governments whose goal is to "develop, collect, and report commonly agreed upon performance measurement data for selected local government services" (Boyer, \& Martin, 2012, p. 125). As these local governments voluntary joined the FBC it is safe to assume that they have concern or interest in performance measurement and management. As such, it warrants examination into their utilization of Facebook for performance related issues. Thirteen cities were randomly selected and all their posts analyzed over a three-month period (October 1 to December 31, 2015). Data was retrieved from each official Facebook page with all posts related to performance measurement or reporting manually recorded. The posts were then coded as push (government to citizens), pull (citizen to government), or networking strategies (citizen to citizen). By assessing the predominant strategies used by each municipality, this research hopes to allow a more nuanced investigation of current municipal performance-related social media application.

\section{Results}

The use of Facebook and the number of posts varied considerably in the sample. The minimum number of posts over the three-month time period was 12 and the maximum number of posts was 149. The total 'likes' (on all posts) that a municipality received ranged from 24 to 28,150 and the total comments ranged from 
2 to 1,430 . This demonstrates that cities range widely in their activity on Facebook. When it comes to the posts that deal with performance issue their activity is significantly lower. The total number of posts that deal with a performance issue range between 0 and 8 , while the total number of likes on its performance posts range between 0 and 595, and total number of comments of all of its posts between 0 and 45. The table below illustrates the total number of performance related posts for each municipality page and the total number of likes and comments these posts received. The table indicates that these 13 cities had a total of 27 performance related posts that received 1,510 likes and 111 comments.

Table

\section{Performance Posts and Strategies}

\begin{tabular}{|c|c|c|c|c|c|c|}
\hline Name of city & $\begin{array}{l}\text { Performance } \\
\text { posts }\end{array}$ & $\begin{array}{l}\text { Total \# } \\
\text { likes }\end{array}$ & $\begin{array}{c}\text { Total \# } \\
\text { comments }\end{array}$ & Push & Pull & Networking \\
\hline City of Cape Coral & 8 & 318 & 40 & 6 & 2 & 0 \\
\hline City of Clermont & 1 & 593 & 45 & 0 & 1 & 0 \\
\hline City of Coral Springs & 0 & 0 & 0 & 0 & 0 & 0 \\
\hline City of Deerfield Beach & 1 & 5 & 3 & 1 & 0 & 0 \\
\hline City of Lakeland & 2 & 244 & 3 & 2 & 0 & 0 \\
\hline City of Largo & 4 & 61 & 2 & 3 & 1 & 0 \\
\hline City of Mount Dora & 1 & 184 & 8 & 1 & 0 & 0 \\
\hline City of New Smyrna Beach & 3 & 11 & 1 & 2 & 1 & 0 \\
\hline City of Oakland Park & 4 & 42 & 6 & 4 & 0 & 0 \\
\hline City of Ormond Beach & 0 & 0 & 0 & 0 & 0 & 0 \\
\hline City of Palm Bay & 1 & 26 & 2 & 1 & 0 & 0 \\
\hline City of Pompano Beach & 0 & 0 & 0 & 0 & 0 & 0 \\
\hline City of Tallahassee & 2 & 26 & 1 & 2 & 0 & 0 \\
\hline Total & 27 & 1510 & 111 & 22 & 5 & 0 \\
\hline
\end{tabular}

The data was further organized to determine the predominant strategy used in the posts. The predominant strategy used by the cities was the push strategy (G2C) with a total number of 22 posts, followed by the pull strategy (C2G) with 5 posts and the networking strategy (C2C) was not used at all. The pull strategies where citizens provide inputs are fewer in number and typically those were initiated by the municipality. The networking types of posts are not used at all. This indicates that citizens do not use municipal Facebook pages for self-organization or initiatives with other citizens.

The performance-related posts, in addition to being analyzed by the dominant strategy used, were also examined for the type of information they convey. The posts that used the push strategy (G2C) were specifically dealing with per- 
formance information related with program achievements, of volunteer group accomplishments, overall performance (rating) of the city and city awards. The posts using the pull strategy asked citizens for input related to plans (transportation or communication plans) or to help the city to achieve the highest food collection or to vote for the city in some type of competition (example: best water tank in the nation).

\section{Discussion}

This study contributes to the growing body of knowledge about citizen involvement and the use of social media in the performance measurement and management (PMM) processes making two significant contributions. First, there is still very low, and almost rudimentary, use of Facebook for performance-related issues. Second, municipalities still use Facebook as a one-way top down communication to inform citizens about specific achievements (on its performance) and with little use of Facebook to obtain citizens' input on performance. Hence, the findings of this study support results of Heikkila \& Isett (2007) who found limited citizen involvement in PMM among special purpose districts and is in line with the findings of Ellison \& Hardey (2013) and Gunawong (2015) who came to the conclusion that local authorities do not use social platforms such as Facebook in a substantive and effective manner. Further, similar to Ellison \& Hardey (2014) where local governments predominantly use the push strategy to share information with citizens, this study comes to the same conclusion.

While the use of Facebook is not the only way to engage citizens in the PMM, it certainly is a cost effective and complementary way to do so. As such, when citizens' comment or network on municipal social media platforms, they may red flag certain issues and bring it to the government's attention in a fast and convenient manner. Moreover, Lev-On \& Steinfeld (2015) argue that increased communication between government and citizens leads to increased trust, and Facebook can play an important role in that relationship. As technology becomes more widespread and dynamic, one can assume the increased use of social media platforms by citizen groups of all ages will better frame a paradigm shift from traditional interactions between municipalities and citizens to an expansion into real-time performance measurement and management collaboration. This study agrees with Woolum (2011) that governments can improve their performance reporting to the public and Facebook may be one avenue to do so. This becomes an even more important premise if one accepts that budgetary and annual reports are rarely read by citizens. Consequently, a succinct albeit informative Facebook post is a highly effective way to inform and engage citizens in performance-related issues. Moreover, Facebook and other social media platforms may also be useful in obtaining information from citizens and facilitating many-to-many communication among citizens. Hence, governments may have the opportunity to use social media platforms to increase the transparency of the policy making process and include citizen viewpoints.

While this study is one of the few studies that examine the use of social media for PMM issues and contributes to the understanding of the use of Facebook for 
performance measurement and reporting, it focuses on a small sample of municipalities and did not include actual perceptions of government employees. Therefore, future studies should include a larger sample of governments and incorporate the views of municipal employees and ask them how they process posts or comments posted on their municipal Facebook page and how they include (or exclude) them from the policy-making or policy changing process. This may provide a closer and more detailed look at the manner in which municipalities process performance-related social media posts.

\section{REFERENCES}

1. Bonsón, E., Royo, S. \& Ratkai, M. (2015). Citizens' Engagement on Local Governments' Facebook Sites. An Empirical Analysis: The Impact of Different Media and Content Types in Western Europe. Government Information Quarterly, vol. 32, no 1, pp. 52-62.

2. Boyer, S.R. \& Martin, L. L. (2012). The Florida Benchmarking Consortium: A Local Government Performance Measurement and Benchmarking Network. Public Performance and Management Review, vol. 36, no 1, pp. 124-137.

3. Dalehite, E.G. (2008). Determinants of Performance Measurement: An Investigation into the Decision to Conduct Citizen Surveys. Public Administration Review, vol. 68, no 5, pp. 891-907.

4. De Lancer Julnes (2013). Citizen-Driven Performance Measurement: Opportunities for Evaluator Collaboration in Support of the New Governance. New Directions for Evaluation, no 137, pp. 81-92.

5. De Zuniga, H.G., Jung N. \& Valenzuela, S. (2012). Social Media Use for News and Individuals' Social Capital, Civic Engagement and Political Participation. Journal of Computer-Mediated Communication, vol. 17, no 3, pp. 319-336.

6. Dimitrijevska-Markoski, T. (forthcoming). The Impact of Performance Measurement and Performance Information Use on Municipal and County Performance. Public Administration Quarterly.

7. Ellison, N. \& Hardey, M. (2013). Developing Political Conversation? Information, Communication and Society, vol. 16, no 6, pp. 878-889.

8. Ellison, N., \& Hardey, M. (2014). Social Media and Local Government: Citizenship, Consumption and Democracy. Local Government Studies, vol. 40, no 1, pp. 21-40.

9. Fung, A. (2015). Putting the Public Back into Governance: The Challenges of Citizen Participation and Its Future. Public Administration Review, vol. 75, no 4, pp. 513-522.

10. Gunawong, P. (2015). Open Government and Social Media: A Focus on Transparency. Social Science Computer Review, vol. 33, no 5, pp. 587-598.

11. Hand, L.C., \& Ching, B.D. (2011). You Have One Friend Request. Administrative Theory \& Praxis, vol. 33, no 3, pp. 362-382. 
12. Heikkila, T. \& Isett, K. R. (2007). Citizen Involvement and Performance Management in Special-Purpose Governments. Public Administration Review, vol. 67, no 2, pp. 238-248.

13. Ho, A.T. (2006). Accounting for the Value of Performance Measurement from the Perspective of Midwestern Mayors. Journal of Public Administration Research and Theory: J-PART, vol. 16, no 2, pp. 217-237.

14. Hofmann, S., Beverungen, D., Räckers, M. \& Becker, J. (2013). What Makes Local Governments' Online Communications Successful? Insights from A Multi-Method Analysis of Facebook. Government Information Quarterly, vol. 30, no 4, pp. 387-396.

15. Holzer, M., \& Kloby, K. (2005). Public Performance Measurement: An Assessment of the State-Of-The-Art and Models for Citizen Participation. International Journal of Productivity and Performance Management, vol. 54, no 7, pp. 517-532.

16. Lev-On, A., \& Steinfeld, N. (2015). Local Engagement Online: Municipal Facebook Pages as Hubs of Interaction. Government Information Quarterly, vol. 32, no 3, pp. 299-307.

17. Linders, D. (2012). From E-Government to We-Government: Defining a Typology for Citizen E-Participation in the Age of Social Media. Government Information Quarterly, vol. 29, no 94 , pp. 446-454

18. Mergel, I. (2013). Social Media Adoption and Resulting Tactics in the U.S. Federal Government. Government Information Quarterly, vol. 30, no 2, pp. 123-130.

19. Mossberger, K., Yonghong, W. \& Crawford, J. (2013). Connecting Citizens and Local Governments? Social Media and Interactivity in Major U.S. Cities. Government Information Quarterly, vol. 30, no 4, 351-358.

20. Pierce, E.L. (2011). Citizen-Informed Performance Measurement and Reporting in Local Government: Key Factors for Effective Democratic Governance. Doctoral Dissertation. Western Michigan University.

21. Woolum, J. (2011). Citizen Involvement in Performance Measurement and Reporting: A Comparative Case Study from Local Government. Public Performance \& Management Review, vol. 35, no 1, pp. 79-102. 